\title{
Message from President
}

It is an immense pleasure to me to publish new peer- reviewed Journal of Health Promotion as an official publication of Health Education Association of Nepal (HEAN). I would like to heartily thank the editorial board, article reviewers, language editors, managerial team, graphic designer and the authors who have provided valuable contributions. The major objectives of HEAN are to support in developing health policies, effective health education procedure, conducting research on health issues, advocating for preventing health, raising people's health issues, raising health awareness, empowering people to promote their health, developing professionalism among health educators and supporting for health promoting schools.

It is realized globally that curative health service is going to be expensive day by day while prevention is better than cure. Health education is the easiest and cheapest way of achieving health by the people. However, the government of Nepal despite the fact that health education is the most important aspect that empowers people to be healthy with their own initiatives has less prioritized preventive health. Without own initiation and conducting positive health behavior optimum health cannot be achieved. Having a healthy life style is the best way of achieving optimum health. Health education inspires and promotes students and community people to maintain health and healthy, life styles.

Health is the most concerning and valued asset of all human beings. People of all age, sex, caste, class, geographical areas, professions and occupations must have minimum knowledge, consciousness, appropriate skills and practices related to personal, family and community health. People are responsible for their own as well as other's health. Health is achieved through right knowledge, positive attitude, healthy behaviors and rationale decisions including access to health facilities and services.

Health is also recognized as human right. Nobody can neglect to students' and other people's right to health. Neglecting health, health information, healthy behaviors and healthy life styles lead to high risk in life. Access to health information, health education and maintenance of healthy behaviors fall under basic human rights. In contrary to this, Nepal's Ministry of Education, Science and Technology has removed health education from compulsory subject in secondary level through the recent modification of School Curriculum Framework, 2075. It is against students' health rights. With this ground reality HEAN has recently handed over a memorandum to the Education Minister with an intention to retain Health and Physical Education as compulsory subject in School Curriculum Framework, 2075.

Health promotion is the newly developed concept. Ottawa Charter (1986) defines health promotion as a process of enabling people to achieve health through acquiring effective health education, creating healthy environment, developing healthy public policies to conducive health and reorienting health services. This journal also reflects the spirit of health promotion as well as the objectives of HEAN. The present Executive Committee of HEAN (Reformed on Paush 16, 2073) had organized a Seminar cum Workshop on Research Methodology and Academic Writing held in Pokhara in 2074 in association with Health, Physical and Population Education Department under P. N. Campus. It has also organized a talk program on Photo-voice as a Qualitative Research Methodology in Health and Population Education Department, Kirtipur in 2075 which was facilitated by Dr. Alexandra Lightfoot from University of North Carolina. Moreover, a two-day National Seminar was organized jointly by HEAN and SOPHES on Comprehensive Sexuality Education in Hillside Hotel, Kirtipur in the same year.

At the end, the present Executive Committee of HEAN requests distinguished, life and general members, advisors, concerning personnel and agencies to give their hands for its further activities and promoting health of the people.

Prof. Shiva Sharan Maharjan, Ph.D.

President, HEAN June, 2018 